\title{
An Interesting Finding in Upper Gastrointestinal Endoscopy
}

\author{
Mohammadreza Seyyedmajidi ${ }^{1}$, Rasoul Shajari ${ }^{2}$, Jamshid Vafaeimanesh ${ }^{2,3, *}$
}

1. Golestan Research Center of Gastroenterology and Hepatology-GRCGH, Golestan University of Medical Sciences, Gorgan, Iran

2. Clinical Research Development Center, Shahid Beheshti Hospital, Qom University of Medical Sciences, Qom, Iran

3. Gastroenterology and Hepatology disease Research Center, Qom University of Medical Sciences, Qom, Iran

* Corresponding Author:

Jamshid Vafaeimanesh, MD

Gastroenterology and Hepatology Diseases Research Center, Qom University of Medical Sciences, Qom, Iran

Tel: + 982536122949

Fax: + 982536122949

Email: jvafaeemanesh@yahoo.com

Received: 26 Dec. 2019

Accepted: 01 Mar. 2020
Please cite this paper as:

Seyyedmajidi MR, Shajari R, Vafaeimanesh J. An Interesting Finding in Upper Gastrointestinal Endoscopy. Middle East J Dig Dis 2020;12:130-132. doi: 10.34172/mejdd.2020.174.

Here we report a case of a 62-year-old man who presented to the gastrointestinal clinic during the past 6 months with symptoms of chronic abdominal pain, accompanied by dyspepsia and weakness. He suffered from type 2 diabetes and hypertension and had received drug treatment for both diseases. Over the past year, he had repeatedly taken non-steroidal anti-inflammatory drugs (NSAIDs) due to arthralgia without the use of gastric acid inhibitors. He refused the presence of melena or bleeding when describing his condition. Physical examination showed that he only had a sensitivity of the upper abdomen, and in blood tests, microcytic anemia with serum iron level 7.1 $\mu \mathrm{g} / \mathrm{dL}$ and iron deficiency with serum ferritin level $10 \mathrm{ng} / \mathrm{mL}$, and hemoglobin $10.1 \mathrm{~g} / \mathrm{L}$ were detected. He was examined for gastrointestinal microcytic anemia and the symptoms. Esophagogastroduodenoscopy showed normal esophagus, erosive gastritis, normal duodenum, and Double pylorus. Colonoscopy was normal. The endoscope passed both channels separately and the bulb of the duodenum was seen. (figure 1). The patient's double pylorus was confirmed by contrast radiography (figure 2). Also, urea testing of rapid Helicobacter pylori was conclusive, while histological studies of the gastric corpus and antrum revealed that chronic active gastritis

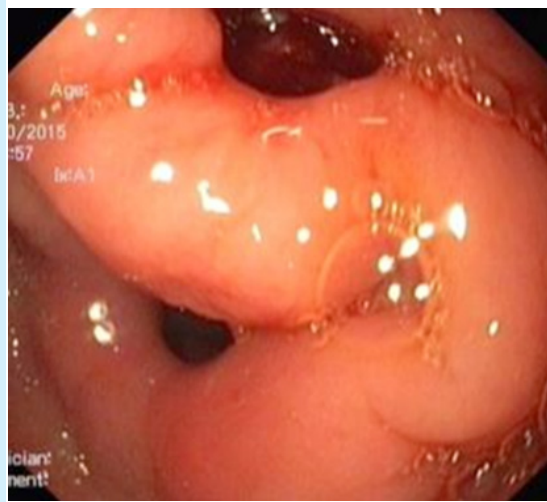

Fig.1: Endoscopy of the patient's pyloric area

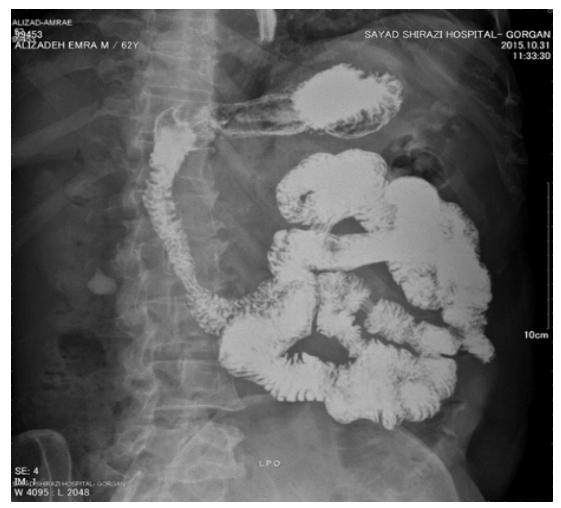

Fig.2: Contrast radiography of the patient was present in both and many Helicobacter pylori bacteria were found in H\&E staining. The patient was treated to eradicate Helicobacter pylori with clarithromycin $500 \mathrm{mg}$, amoxicillin $1 \mathrm{~g}$, and omeprazole $20 \mathrm{mg}$, twice daily for 14 days. Eradication was confirmed by a carbon-13 breath test, two months after treatment. Proton pump inhibitors were continued to be used once daily and NSAIDs use was restricted. Symptoms disappeared after a few weeks of treatment

cc) (1) $\$ 2020$ The Author(s). This work is published by Middle East Journal of Digestive Diseaes as an open access article distributed under the terms of the Creative Commons Attribution License (https://creativecommons. org/licenses/by-nc/4.0/). Non-commercial uses of the work are permitted, provided the original work is properly cited 
and the patient's anemia normalized after 6 months of treatment with the iron pill.

What is your diagnosis?

\section{Answer: Acquired double pylorus}

\section{CONCLUSION}

Double pylorus (DP) is a rare disease caused by a gastrointestinal fistula that spreads from the gastric antrum to the duodenal bulb. This rare disease may be acquired or congenital. ${ }^{1-2}$ The primary cause of congenital DP $(\mathrm{CDP})^{1}$ was described by Christine in 1971 and only a few cases have been reported since then. In the CDP, defects in pyloric canal formation appear in the initial stages of embryonic life. ${ }^{3}$

However, presented cases occur in gastric cancer or as a complication of gastric ulcer and as a result of the formation of a fistula between the antrum and the duodenal bulb or prepyloric region. ${ }^{4}$ This rare anomaly is observed in $0.001 \%$ to $0.4 \%$ of endoscopic cases. ${ }^{5}$

Acquired $\mathrm{DP}^{2}$ alone has no specific clinical manifestation and can present withvomiting, abdominal pain, gastrointestinal bleeding, and dyspepsia ${ }^{6}$ as a result ofconcomitant gastric ulcer or other diseases.

The diagnosis of this lesion could be endoscopically considered. In the endoscopic examination, the antrum should adequately open by air to make the fistula visible through the thickened gastric folds. Most fistulas lie on the small curvature of the gastric antrum.

At endoscopy, the gastric antrum may appear normal ${ }^{1}$ and in some cases, inflammation or scarring is also seen. ${ }^{7}$ Enough air needs to be blown into the stomach to open the gastric folds and see the fistula if present. The size of the fistula may vary from millimeters to a few centimeters, and in many patients, these fistulas are based in the small curvature of the upper wall of the duodenal bulb and thegastric antrum. ${ }^{2}$

Although the DP has a definite appearance at endoscopy, it may be easily misdiagnosed with gastric diverticulum or the double pylorus may be reported as a polyp, tumor, or a large mucosal fold in upper gastrointestinal endoscopy.

1. Congenital double pylorus

2. Acquired double pylorus
As reported in a study by $\mathrm{Hu}$ and colleagues ${ }^{2}$ who followed patients with DP, the secondary pyloric canal remained in most cases (about $60 \%$ of patients) throughout the patient's lifetime; however, in some of the patients $(25 \%)$, lateral pylorus was occluded or sometimes (only $5 \%$ of patients) a communication was established with the real pylorus and a canal was formed..$^{2-8}$

Various mechanisms and reasons have been proposed for creating acquired pylorus. Some researchers believe that gastric mucosal microcirculation following systemic diseases such as diabetes, chronic pulmonary disease, rheumatoid arthritis, cirrhosis, systemic lupus erythematous, and chronic kidney failure may be associated with acquired DP. 9,10

It has also been suggested that a long history of treatment with drugs, including corticosteroids and NSAIDs, can influence the course of gastric ulcer. Helicobacter pylori play an important role in the pathogenesis of duodenal ulcer and most gastric peptic diseases. Helicobacter pylori are potentially responsible for refractory and non-healing peptic ulcer cases. ${ }^{11}$ The mentioned mechanisms or their combination can cause non-healing gastric ulcers and its complications over time and in rare cases cause fistula and pyloric duodenum. DP can rarely cause gastric outlet obstruction. ${ }^{12}$

Treatment of patients with DP should focus on removing the factors that affect mucosal healing of gastric ulcers. In some cases, endoscopic treatment may be performed using biliary sphincterotomy to divide the living bridge tissue. Surgical procedures should be used for patients who may not receive endoscopic treatment or patients with refractory symptoms such as recurrent ulcers or repeated bleeding with adequate drug treatment with proton pump inhibitors. ${ }^{13}$ Table 1 summarizes the patients' characteristics and features of the DP.

\section{ACKNOWLEDGMENTS}

There is nothing to be declared. (Informed consent was taken from the patient)

\section{CONFLICT OF INTEREST}

The authors declared no conflict of interest related to this research. 
Table 1: Summary of the patients' characteristics with double pylorus

\begin{tabular}{|c|c|}
\hline Patients' characteristics & $\begin{array}{l}\text { Chronic abdominal pain, vomiting, dyspepsia, and gastrointestinal bleeding due to concomitant } \\
\text { gastric ulcers or other diseases. }\end{array}$ \\
\hline Risk factors & $\begin{array}{l}\text { Use of drugs causing ulcers, adrenal adenoma, Helicobacter pylori, diabetes, chronic obstructive pulmo- } \\
\text { nary disease, chronic kidney failure, Behcet's disease }\end{array}$ \\
\hline Reasons (for causing the disease) & duodenal ulcer, gastric cancer, gastric ulcer \\
\hline Incidence rate & $0.001 \%$ to $0.4 \%$ of upper gastrointestinal endoscopy \\
\hline Complications & Gastric outlet obstruction, refractory gastric ulcer \\
\hline Laboratory findings & $\begin{array}{l}\text { Blood biochemistry and complete blood count are usually normal, but in patients with gastrointestinal } \\
\text { bleeding, complete blood counts may indicate anemia and blood biochemistry may indicate intravenous } \\
\text { azotemia (e.g. increased normal creatinine and blood urea nitrogen). Helicobacter pylori test results are } \\
\text { often positive. }\end{array}$ \\
\hline Differential diagnosis & Gastric diverticulum \\
\hline Treatment & Drugs, endoscopic or surgical treatment \\
\hline
\end{tabular}

\section{REFERENCES}

1. Wiseman SM, Tan D, Hill HC. Double pylorus: an unusual endoscopic finding. Endoscopy 2005;37: 277. doi: $10.1055 / \mathrm{s}-2005-861016$

2. Hu TH, Tsai TL, Hsu CC, Lu SN, Hsiao M, Changchien CS. Clinical characteristics of the double pylorus. Gastrointest Endosc 2001;54: 464-70.doi: 10.1067/mge.2001.117543]

3. Wolters VM, Nikkels PG, Van Der Zee DC, Kramer PP, De Schryver JE, Reijnen IG, et al. A gastric diverticulum containing pancreatic tissue and presenting as congenital double pylorus: case report and review of the literature. $J$ Pediatr Gastroenterol Nutr 2001;33:89-91.doi: 10.10 97/00005176-200107000-00017]

4. Umar S, Bilal M. Double pylorus: two sides to one story. Clin Case Rep 2016;4:1211-2. doi:10.1002/ccr3.730

5. Safatle-Ribeiro AV, Ribeiro Júnior U, Habr-Gama A, GamaRodrigues JJ. Double pylorus: case report and review of the literature. Rev Hosp Clin Fac Med Sao Paulo 1999; 54:131-4. doi: 10.1590/S0041-87811999000400006]

6. Arhan M, Oztas E, Ibis M, Sezgin S, Ozin Y. A rare endoscopic finding: acquired double pylorus. Surg Endosc 2010; 24:244-5. doi: 10.1007/s00464-009-0557-5

7. Almeida N, Romãozinho JM, Ferreira M, Amaro P, Tomé $\mathrm{L}$, Gouveia H, et al. Double pylorus with bleeding gastric ulcer - a rare event. Rev Esp Enferm Dig 2008;100:600-1. doi: $10.4321 / \mathrm{S} 1130-01082008000900018$

8. Akazawa Y, Mizuta Y, Okabe M, Nakamura T, Morikawa $\mathrm{S}$, Isomoto $\mathrm{H}$, et al. A case of double pylorus caused by recurrent gastric ulcers: a long-term endoscopic observation. Dig Dis Sci 2005;50:2125-8.doi: 10.1007/s10620-0053018-6]

9. Czajkowski A, Rosołowski M, Lukaszyk A. Double pylorus: strong evidence for the acquired etiology of this rare abnormality. Endoscopy 2007;39 Suppl 1: e84. doi: 10.1055/ s-2006-945080]

10. Hatemi I, Hatemi G, Erzin YZ, Celik AF. Double pylorus in a patient with Behcet's syndrome. Clin Exp Rheumatol 2015;33:S138-40.
11. Lei JJ, Zhou L, Liu Q, Xu CF. Acquired double pylorus: Clinical and endoscopic characteristics and four-year follow-up observations. World J Gastroenterol 2016; 22:2153-8. doi: 10.3748/wjg.v22.i6.2153.

12. Goh BK, Tan HK. Double pylorus. Am J Surg 2006;191:515-6. doi:10.1016/j.amjsurg.2005.10.024

13. Graham SM, Lin F, Flowers JL. Symptomatic double-channel pylorus. Successful treatment with a biliary sphincterotome. Surg Endosc 1994;8:792-793. doi:10.1007/ bf00593443 